\section{Brand PR: \\ Comunicaciones de marca}

Damián Martínez Lahitou ${ }^{(*)}$

Resumen: En este artículo se reflexiona acerca de las Brand PR o la Comunicación de Marca, y en cómo las Relaciones Públicas pueden contribuir a establecer una conexión emocional entre ellas y las personas. En este sentido, se delinea un cambio en los mercados en el cual se configura un nuevo paradigma de comunicación -al que aún hay que interpretar- que busca lograr esas conexiones de una forma significativa, valiosa y perdurable. $Y$ un nuevo consumidor, nuevas tecnologías e ideas que implican un conocimiento cada vez más profundo y complejo. Es decir, un panorama desafiante y confuso a la vez, con muchos elementos nuevos que se deben conectar entre sí. Y un nuevo rol y destrezas para las Relaciones Públicas que sin dudas, hoy atraviesan una redefinición histórica, revalorizándose por su capacidad amplificadora sincrónica: la capacidad de amplificar el esfuerzo de la marca en sincronía, en el mismo momento y lugar que lo hacen el resto de las comunicaciones de marketing.

Palabras claves: Brand PR - campañas publicitarias - Comunicaciones Corporativas - Comunicaciones de Marca - Comunicación Empresaria - comunicadores - Dircom - gestión comunicacional - Imagen Corporativa - Marcas - Marketing - medios de comunicación - Mercadeo - nuevas tecnologías - públicos - Relaciones Públicas - Reputación Corporativa - social media - stakeholders.

[Resúmenes en inglés y portugués y currículum en las páginas 29-30]

Había una vez.... Poco a poco fue apareciendo en el mercado. Con bajo perfil. Parecía sólo una moda y finalmente llegó para quedarse.

Como pasa habitualmente, fue paso a paso, con dificultades, con grandes defensores, facilitadores y también con muchos detractores. Pero llegó.

Hoy se observan los avances que las comunicaciones de marcas han hecho en el terreno de la publicidad, su irrupción (y triunfos) en los medios digitales, la forma en la que usan la creatividad, las ideas poderosas y las nuevas conexiones que establecen con las mentes y con los corazones de las personas.

Las Relaciones Públicas deberían aprender de esto, y salirse de la zona de comodidad. Lo que se ha hecho hasta ahora está muy bien hecho, y lo que se sabe se hace muy bien. Pero está faltando algo. No, mejor dicho, si las cosas se siguen moviendo en la dirección en que se están moviendo, en el futuro nos va a faltar una columna importante. Aquella con la que las Relaciones Públicas pueden apoyar a las marcas para ayudarlas a conectarse con las personas emocionalmente. Las herramientas que -aunque todavía suenen lejanas- las $P R$ pueden aportar para lograr esas 
conexiones de una forma significativa, valiosa y perdurable.

Hay un cambio claro en el mercado y la intención de este artículo es mostrarlo. ¿Cuál es? Llegó el momento de hablar de Brand PR.

\section{Hola, llegó un nuevo paradigma}

Es canchero ser el nuevo paradigma. Porque la palabra paradigma es linda: académica, compleja pero fácil de pronunciar. Porque suena a algo siempre allá arriba, medio inalcanzable pero sin soberbia, cambiante, novedoso, deseado... (Y en definitiva, porque es mucho mejor -en todo caso- que ser por ejemplo un apotegma). Al fin: ¿quién no quisiera ser un paradigma? El punto es que esta vez, lindo y canchero como siempre, el nuevo paradigma es de verdad incomprensible. $\mathrm{O}$ al menos difícil de abarcar, de aprehender y de entender.

Así, se reconfiguran en él muchos elementos: un nuevo consumidor, nuevas tecnologías, ideas novedosas. Y también un conocimiento cada vez más profundo y complejo sobre todos ellos. Es decir, un intríngulis para todos los que venimos 'haciendo eso que hacemos' desde hace unos cuantos años.

Es un panorama fascinante, pero confuso, con muchos elementos nuevos que se deben conectar entre sí (y con los que ya conocíamos). Lo bueno es que de todos estos, podemos aislar los elementos más importantes para nuestro sistema: H2O. Y en comunicaciones: medios - consumidores - marca.

El viejo paradigma era, podría decirse, militar, verticalista, unívoco. Las marcas hablaban, el consumidor escuchaba y obedecía. Era un consumidor espectador, frustrado, sin canales de conversación o de respuesta hacia las marcas. Se expresaba cada tanto, en una carta de lectores en el diario. Sin canales de comunicación abiertos, los consumidores vivían sin vínculos verdaderos entre ellos y con las marcas.

Es fácil pensar que el cambio ha surgido con la aparición de las herramientas tecnológicas de la web 2.0, los móviles y los medios digitales. Pero se entiende que el cambio es todavía más profundo. Es un cambio actitudinal, mental y conceptual.

Pareciera que los seres humanos se están parando distinto frente a las cuestiones que hacen a realidad cotidiana. También, frente a los hechos que los conmueven. $\mathrm{O}$, mejor dicho, estamos eligiendo qué cosas nos van a conmover.

Acá y en todo el mundo, se discute a quiénes se tienen de líderes, no se aceptan los dogmas, se pelea por los ideales, se consensúan las ideas. Si se lo hace con las instituciones o los gobiernos, ¿cómo no hacerlo con las marcas?

La tecnología ayuda, claro, pero sería como decir que el Renacimiento se debió a que apareció la imprenta o que la Edad Moderna surgió solamente como consecuencia de la aparición de la locomotora a vapor. Es pedirle demasiado a la tecnología, y perder el foco. Y el foco está en las personas. Y en cada uno de nosotros.

Y es que hasta ahora, el uso de los nuevos espacios de expresión ha venido desde las personas, no desde las marcas. Fue en los foros, los blogs, los flogs, los $v$-logs, los chats, etc... donde surgió esta nueva corriente. El cambio surgió en YouTube o en Flickr, no en Coke.com o Nike.com, por poner el caso de los de las empresas que mejor manejan hoy el espacio digital.

Tal vez si fuera por quienes manejan -o manejamos- marcas, nada de esto habría ocurrido. El 
cambio no vino de las marcas ni tampoco de la tecnología. Vino de un cambio de pensamiento, de actitudes. Vino de las personas. Viene de de cada uno de nosotros.

Y eso implica repensar el viejo esquema de la comunicación, donde había un emisor, un código común, un canal, un mensaje y un receptor. Ahora es el receptor quien impone el código. Y quien elige el medio (o canal) en el cual expresarse.

Desde el punto de vista de las marcas, no sólo la marca emite y el consumidor recibe, sino que el consumidor responde. Y no sólo responde, el receptor dialoga con otros receptores sobre ese emisor inicial, es decir, la marca.

Por eso es que hoy las marcas están desesperadas por 'establecer conversaciones' con los consumidores. Y en realidad lo que hacen es intervenir -algunas muy bien, otras muy mal, la mayoría con temor- en esas conversaciones entre las personas. $Y$ en los espacios donde tienen lugar esas conversaciones. De ahí que uno de los componentes más importantes de este nuevo paradigma sea -precisamente- la capacidad de entablar conversaciones entre las marcas y las personas, de la misma manera que las personas lo hacen entre sí.

Pensemos un minuto en Nike. Cuando tuvo que dejar de ser un producto selecto y de nicho, consumido por unos pocos ultra-atletas, no solamente se dirigió a las personas a través la web, sino que utilizó esta herramienta para crear relaciones sostenidas y de ida y vuelta con ellas. Es más, hizo que las personas hablaran entre sí a través de la marca, como la acción en la que un amigo podía establecer contacto por celular a través de personajes famosos. Eso se llama diálogo. Diálogo en serio.

Hay otro cambio del que hay que ocuparse: lo que ocurre en los medios. Un comité de expertos se reunió en Europa para conversar sobre dos temas que angustian a los periodistas, editores y generadores de contenidos. Uno, la desaparición de los medios impresos en papel. Dos, el impacto de las nuevas tecnologías en los medios.

Mientras estos expertos discutían, ocurrió algo terrible: cayó Lehman Brothers. Las finanzas mundiales se desplomaron. El consumo de evaporó. La publicidad desapareció de los medios y los despidos comenzaron a sentirse. Los periodistas comenzaron a quedarse sin trabajo. Peor aún, los medios comenzaron a quedarse sin periodistas.

Está claro que quienes formamos el sector de agencias de las $P R$ somos una opción para remodelar el orden imperante de nuestra política y la economía.

La revista The Nation de los Estados Unidos, en diciembre de 2009, publicó este pedido urgente de ayuda a sus lectores:

A medida que las salas de redacción se reducen y los sistemas de infotainment se propagan, el compromiso de The Nation de mantener una actitud vigilante, y un periodismo tellit-like-it-is de investigación permanece inquebrantable. Pero es posible sólo con el apoyo adicional de nuestros lectores. (The Nation, 2009)

¿Entonces? ¿Existe allí una oportunidad para las marcas? ¿Hay algo más de valor que se pueda aportar desde las Relaciones Públicas?

La visión de varios de los editores de medios grandes y medianos en los Estados Unidos, es que una vez que la crisis se termine los ingresos volverán sólo hasta el $80 \%$ de lo que eran en 2007 . Y el ratio de ingresos de los medios, que antes era de 6 a 4 entre publicidad e ingresos por lectores, ahora serán de 9 a 1 . Ahora, si los ingresos viene sólo por publicidad se preguntan los editors y 
publishers, ¿cuánto falta para que sean las marcas y no los media groups los dueños de esos medios? ¿Cuánto falta para que GM o Unilever o Gillette sean dueños de medios, de la misma forma que hoy lo son Time Warner, CNN o Fox Media? Esa es la pregunta que se hacen los gerentes de medios, y los anunciantes. También se la hacen los periodistas, que ya trabajan para marcas, tanto como para medios."

Suponiendo que es un punto de vista exagerado y que sus interlocutores en los Estados Unidos estaban demasiado preocupados. Igualmente hay varios puntos interesantes allí:

- ¿Pueden las marcas transformarse en generadoras de contenidos para los medios?

- ¿Pueden ayudar a los medios a tener historias interesantes para contar a sus lectores (se llamen así a televidentes, radioescuchas, internautas, mobile readers, etc.) y atraer más audiencias?

- ¿Son las marcas objeto de noticia? ¿Tienen valor periodístico para los medios?

- ¿Pueden las marcas usar ese empuje para establecer nuevas, mejores y más profundas relaciones con sus consumidores?

La función de las Brand $P R$ es transformar a las marcas en grandes y buenos productores para los medios. No compitiendo ni entrometiéndose (la independencia entre periodismo y empresa periodística tiene que ser respetada con cada vez más fuerza), sino cooperando. Generando conexiones emocionales fuertes entre marcas y personas. Generando contenidos interesantes que unan y reúnan a los medios con sus lectores. Y generando ROI interesantes para las marcas. Y esto, va a llevar a los profesionales de las Relaciones Públicas a trabajar sobre dos cuestiones muy importantes. La redefinición de lo que es noticia y si las marcas pueden ser objeto de noticia.

\section{Las nuevas comunicaciones de marca}

El nuevo paradigma no es algo abstracto o pasajero. Ya avanza entre nosotros y tiene un impacto directo en la forma en la que las organizaciones, empresas y marcas se comunican con las personas. El territorio de las marcas se expande y se abre. Las relaciones con los consumidores se van haciendo cada vez más emocionales. Los vínculos emocionales son, por definición, inestables y complejos. Esto dice mucho sobre la forma en la que las personas van a relacionarse en el futuro con las marcas y con las instituciones: de la misma forma caótica, apasionada y desordenada en que manejan sus relaciones personales.

Eso es bueno, pero también es riesgoso. Se ingresa en un territorio apasionante, sí; pero también complicado. Los nuevos mundos son así.

El consumidor se pone más exigente, más inteligente, más brand-savy, más emocional, más consciente de su poder de compra (y de daño) y más activo. Las marcas se vuelven (o deberían volverse) más activas y abiertas. Y las comunicaciones dejan de ser lineales y abstractas.

Se murió -pobrecita- la frase "El mensaje que baja la marca". Hoy, el consumidor le revolea SU mensaje a la marca. Así, hoy las palabras clave de las comunicaciones son: 
- Credibilidad

- Planning

- Insights

- Storytelling

- Cambio

- Horizontalidad

- Feedback

- Engagement

¿Qué quiere decir esto para el mercado de $P R$ ? Hasta hoy, $P R$ estaba enfocado en dos temas centrales. Construcción de reputación y manejo de crisis. Pero hay un territorio emergente.

Hay un nuevo lugar en donde se encuentran las necesidades crecientes de las marcas de relacionarse con las personas, de ser impactantes y relevantes y lo que se hace desde las Relaciones Públicas. Se puede llamar a gusto: territorio, disciplina, evolución, herramienta...

Eso nuevo que está apareciendo (y hoy está en el escritorio de los brand managers más influyentes) se llama Brand PR.

Antes, cuando una marca iniciaba un plan de marketing, ponía a las $P R$ como último elemento. Se cubría la campaña, salía una mención en la página de Empresas-Protagonistas de los medios, y listo. Hoy, las empresas que lideran el cambio suman al equipo de $P R$ a la mesa de trabajo desde el día uno. ¿Por qué? Básicamente, por la capacidad amplificadora sincrónica que tiene $P R$. Es decir, la capacidad de amplificar el esfuerzo de la marca en sincronía, en el mismo momento y lugar que lo hacen el resto de las comunicaciones de marketing, publicidad, web, activaciones, BTL y marketing directo entre otras.

Antes, la amplificación era diacrónica -es decir, fuera de tiempo-. Antes o después, las acciones de $P R$ hablaban sobre la marca o sobre la campaña, pero no generaban impacto para la marca. Lo que hoy debe empezar a buscar el relacionista público es cómo transformar el hecho de marca en una noticia. Hay que lograr que la marca signifique algo para los lectores. Y que sea más que un anunciante para los medios, que en muchos casos, están redefiniendo y ampliando qué es editorial y qué es comercial.

La pregunta que nos hacíamos los 'prenseros' era: ¿cómo hago para que la gacetilla entre en los medios?

Esa pregunta pregunta creció y pasó a ser: ¿cómo hago para que esta gacetilla sea relevante y cuente algo interesante para el medio y sus lectores?

Pero la pregunta que hay que hacerse ahora es: ¿Qué le aporta esta información a la marca? y ¿Cómo le llega esta información al consumidor de una forma relevante y atractiva?

Las Relaciones Públicas tienen que pensar en cómo su trabajo llega al consumidor, de la misma forma en que lo hacen una web, un spot de TV, una frase de radio o una activación. Las $P R$ tienen que ser un aliado del medio, no un simple 'llevador de noticias de prensa'.

En cierta forma, nos tenemos bien ganado el apodo de 'prenseros'. 'Prensero' suena a alguien que hace algo útil, sí; pero que no aporta demasiado valor. Eso no puede seguir siendo así.

Hay que transformarse en aliados de los medios. Oír el llamado de los cientos de periodistas que se la pasan buscando y pidiendo buenas historias. Ayudar a los medios a tener mejores historias y a los periodistas a conseguir mejor material para esas historias. Ayudarlos a lucirse, a conseguir lectores, a seguir mejorando su nivel. Las marcas tienen mucho que dar y mucho 
que ganar. Pero casi no lo hacen, porque desde las agencias de $P R$ no se comenzó, en general, a trabajar en ese sentido.

Pero el viento y la marea están cambiando. Le pasó a la publicidad en los años ochenta, cuando descubrió que debía salir del acartonamiento, de los lugares comunes y de la seriedad para explorar los territorios de la alta creatividad, de la atracción, de la creación de experiencias para las personas.

Hubo un día -en septiembre de 1991, para ser más precisos- en que Coca Cola dejó de pedirle creatividad exclusivamente a McCann Erickson-su agencia desde 1955-, y comenzó a pedírsela a empresas como Creative Arts Agency, CAA, que empezó -además-, siendo una agencia de guionistas de Hollywood.

¿Por qué? "Cada vez que se rompe el molde tradicional, se causa algo de dolor y algunos trastornos -dijo en ese momento Donald R. Keough, Presidente y CEO, de Coca Cola, en una conferencia de prensa en agosto de 1993, cuando CAA presentó la campaña Always Coca Cola -. Reconocemos eso, pero pensamos que necesitábamos una nueva visión del producto creativo." (Keough, 1993).

Peter S. Sealey, vicepresidente y director de marketing global, dijo en ese momento: "Esto podría ser un nuevo paradigma de publicidad. Somos una compañía mejor cuando tenemos un buen competidor. Madison Avenue también será mejor ahora. ¿Por qué tener miedo de la creatividad? Abramos la puerta y dejemos que entre el sol". (Sealey, 1993). A veces, viendo cómo se comporta el sector de las $P R$, pareciera que el sol no está entrando del todo.

El Brand PR está naciendo, no es una categoría desarrollada ni explorada. Pero a medida que las marcas van descubriendo cómo las herramientas de $P R$ pueden ayudarlas a relacionarse más y mejor con sus consumidores, adaptarse es cada vez más necesario. $P R$ terminará siendo una industria creativa por necesidad. Pero creo que debe serlo por voluntad. Por ganas de trabajar mejor. Las Relaciones Públicas tienen las de ganar en este cambio si se ponen las ganas de aprovechar varias cosas que los argentinos tenemos en buenas cantidades:

-Caos y confusión

-Presión y competencia

-Pensamiento lateral

-Inseguridad e incertidumbre

-Talento

Es decir: creatividad.

En ese sentido (y esto puede no gustarle a algunos), hay agencias de $P R$ que atrasan. Ven el cambio como una amenaza. No es grave, siempre pasa. Lo nuevo causa resistencia. Lo grave es que mientras algunas empresas atrasan, los anunciantes y los consumidores se adelantan. Ven y van varios pasos antes que nosotros.

¿Cómo es que hoy hay agencias de publicidad que venden campañas de publicidad globales creadas desde Buenos Aires y no hay una sola agencia de $P R$ que haga algo parecido? Es simple: todavía no lo necesitamos (o eso creen algunos).

Cada tanto, algunos ejecutivos de empresas de $P R$ empiezan a hablar de $P R$ 2.0, de "lo digital", 
de redes sociales. Como si la tecnología fuera una fuerza per se. Un fin y no un medio. Y la fuerza la tiene la gente, y la tienen las ideas que conectan con esa gente. El fin es conectar a las marcas con esa gente.

$¿$ Es acaso el Brand $P R$ un movimiento de contracultura, un emergente vanguardista, rechazado por el establishment? No me animaría a decir rechazado. Pero sí ignorado en muchos casos. Por suerte, el marketing, los anunciantes y la publicidad no lo hacen.

Así, se debería de aprender de la publicidad, y cooperar con cualquier herramienta de comunicación que esté buscando hacer lo mismo que nosotros. Crear valor simbólico para las marcas. Crear valor para las marcas. Crear marcas. Y crear.

El nuevo paradigma está -icuándo no?- haciendo todo lo posible porque no se lo comprenda. No se va a encontrar por ahora, ni en los próximos años, una respuesta clara, pero es importante que se tengan claras esas preguntas, para ir respondiéndolas a medida que vamos recorriendo este, como pocas veces, nuevo paradigma. Que como ya se dijo, es un término muy canchero.

\section{Referencias Bibliográficas}

The Nation (diciembre, 2009). Disponible en www.thenation.com Keough, D. (1993). Presentación de la campaña Always Coca Cola. Conferencia de prensa. Sealey, P. (1993). Presentación de la campaña Always Coca Cola. Conferencia de prensa.

Summary: The article makes a reflection about Brand PR and how public relations can contribute to establish an emotional connection between brands and consumers. In this sense, a change in the markets is delineated in which a new communication paradigm is built that fosters to establish those connections in a significant, valuable and lasting way. In addition, new consumers, new technologies and new ideas imply a deeper and more complex knowledge. A challenging and confused scenario with many new elements that have to connect to each other. And a new role and skills for the public relations that today goes through an historical redefinition, revaluing itself by its synchronous amplifying capacity: the capacity to amplify the effort of brands simultaneously to other marketing communications.

Key words: advertising campaigns - brand - Brand Communications - Brand PR - communication management - communicators - Corporate Communications - Corporate Image Corporate Reputation - Dircom - Marketing - mass media - new technologies - public - Public Relations - social media - stakeholders.

Resumo: Neste artigo se reflexiona a respeito das Brand PR ou a Comunicação de Marca, e em como as relações públicas podem contribuir a estabelecer uma conexão emocional entre elas e as pessoas. Neste sentido, delineia-se uma mudança nos mercados no qual se configura um novo paradigma de comunicação -ao que ainda ha de interpretar- que procura conseguir essas conexões de uma forma significativa, valiosa e perdurável. E um novo consumidor, novas tecnologias e idéias que implicam um conhecimento cada vez mais profundo e complexo. Isto é, um panorama desafiante e confuso ao mesmo tempo, com muitos elementos novos que 
devem-se conectar. E um novo papel e destrezas para as relações públicas que sem dúvidas, hoje atravessam uma redefinição histórica, revalorizando-se por sua capacidade amplificadora sincrônica: a capacidade de amplificar o esforço da marca em sincronia, no mesmo momento e lugar que o fazem o resto das comunicações de marketing.

Palavras chave: Brand PR - campanhas publicitárias - Comunicações corporativas - Comunicações de Marca - Comunicação empresária - comunicadores - Dircom - gestão comunicacional - imagem corporativa - Marcas - Marketing - meios de comunicação - novas tecnologias - públicos - Relações Públicas - Reputação Corporativa - social media - stakeholders.

${ }^{*}$ ) Master en Dirección de Comunicación (Universidad Austral). También complementó su educación con diversos cursos y seminarios sobre Marketing, Comunicación y Gestión de Crisis y Asuntos Públicos. [Ver CV completo en la página 139] 